\title{
História de Vida de Líderes Surdos: um Estudo a Partir da sua Trajetória em Movimentos Sociais ${ }^{1}$ \\ Stories of DeAf Leaders LIVES: a Study of Their Careers in Social MOVEMENTS
}

\author{
Norma Abreu e Lima Maciel de Lemos VASCONCELOS ${ }^{2}$ \\ Elsie Alejandrina Pérez SERRANO ${ }^{3}$ \\ Enicéia Gonçalves MENDES ${ }^{4}$ \\ Juliane Aparecida de Paula Perez CAMPOS 5
}

\begin{abstract}
RESUMO: este artigo trata de histórias de vida de pessoas surdas, tendo como principal objetivo analisar os fatores que as levaram à militância e ao envolvimento em movimentos sociais, assim como as contribuiçóes trazidas pelas suas consequentes lideranças. Como procedimento metodológico, privilegiamos a metodologia História de Vida, através da aplicação de entrevistas abertas e semiestruturadas. Os resultados apontaram como fatores de destaque a influência de "um outro", especificamente um "outro surdo", os aspectos linguísticos, a escola especial para surdos, a igreja e ênfase nas lideranças das pessoas surdas. Como conclusão, os dados analisados nos permitem sugerir que é importante dar voz e oportunidades às pessoas surdas e instigar a sociedade para novos olhares, novos estudos e pesquisas com novas experiências, que sirvam de referenciais como inclusáo de pessoas surdas em movimentos sociais.
\end{abstract}

PALAVRAS-CHAVE: Educação Especial. História de Vida. Líderes Surdos. Movimentos Sociais.

\begin{abstract}
This article addresses stories of deaf people lives, having as main objective to analyze factors that led them to militancy and involvement with social movements, as well as the contributions brought by their consequent leaderships. As methodological procedure, we emphasized the Life History methodology, through the application of open and semi structured interviews. The results pointed as prominent factors the influence of "one other", specifically one "other deaf", the linguistic aspects, the special school for the deaf, the church and emphasis on deaf people leadership. As conclusion, the analyzed data allow us to suggest that it is important to give voice and opportunities to deaf people and to instigate society for new looks, new studies and research with new experiences, which can be used as reference to the inclusion of deaf people in social movements.
\end{abstract}

KEYWORDS: Special Education. Life History. Deaf Leaders. Social Movements.

\section{INTRODUÇÁo}

Relatos históricos mostram que ao longo da história da civilização, pessoas com deficiência foram excluídas dos mais diferentes espaços sociais, isoladas, rotuladas; amargavam preconceitos e discriminação, que se estabelecia desde a descoberta da sua deficiência. Foram

\footnotetext{
${ }^{1}$ http://dx.doi.org/10.1590/S1413-65382216000100007

${ }^{2}$ Doutoranda do Programa de Pós-Graduação em Educação Especial, Universidade Federal de São Carlos, São Carlos, SP, Brasil. normamvasconcelos@yahoo.com.br

${ }^{3}$ Doutora Professora Visitante CAPES pelo Programa de Pós Graduação em Educação Especial da Universidade Federal de São Carlos, São Carlos, SP, Brasil. elsieperezserrano@gmail.com

${ }^{4}$ Doutora e Docente do Programa de Pós-Graduação em Educação Especial, Universidade Federal de São Carlos, São Carlos, SP, Brasil.eniceia.mendes@hotmail.com

${ }^{5}$ Doutora e Docente do Programa de Pós-Graduação em Educação Especial, Universidade Federal de São Carlos, São Carlos, SP, Brasil. jappcampos@gmail.com
} 
vítimas de marginalização, que em determinados momentos eram (se é que ainda não são) vistas como "doentes" e "incapazes”. Documentos como as Diretrizes Nacionais para a Educação Especial na Educação Básica ressaltam ainda, que no imaginário coletivo, "ocupavam a posição de alvos da caridade popular e da assistência social e não de sujeitos de direitos sociais, entre os quais se inclui o direito à educação" (BRASIL, 2001, p.19).

Nesse contexto, Beyer (2006) afirma que "cada vez mais aumentam as pressóes sociais no sentido de abertura de espaços para que essas pessoas saíssem dos espaços segregados" (p.11). Para este autor, a convivência com as diferenças tem o intuito de promover um ambiente rico em situaçóes de pluralidade para a formação de sujeitos mais flexíveis e mais abertas ao convívio social.

Nessa direção, surge um novo momento social impulsionado pela globalização e seus efeitos desafiadores anunciam transformaçóes das mais diversas possíveis e, segundo estudos e pesquisas, vem ocasionando impacto sobre as pessoas com deficiência que, por sua vez, buscam serem atores e autores da sua própria história, da sua própria vida. Sem poder apagar a sua história, mas podendo reconstruí-la, buscam um modelo que venha contemplar de fato a todo o cidadão, um cidadão de direito e de fala.

Piccolo e Mendes (2013) afirmam que "[...] se é a sociedade que incapacita as pessoas com deficiência, a única forma de estas alterarem tal situação é mediante intensas lutas para transformar o estado atual de forças e assumirem o controle sobre suas próprias vidas (p.465)". Entretanto, há de se concordar que conquistas e transformaçóes aconteceram e intensas lutas foram travadas para assumir e modificar a realidade exposta.

Nesse cenário, destaca-se o Disability Studies, um grupo londrino de teóricos ativistas com deficiência, que promovem estudos sobre tal, percebendo a deficiência enquanto modelo social, reconhecendo - a como uma questão de direitos sociais. Este grupo vem mostrar à sociedade que pessoas com deficiência não são "uma forma de tragédia pessoal" e sim, pessoas de direito e valor social, ou seja, vem apresentar um novo modelo, o modelo social da deficiência. Piccolo e Mendes (2013) acrescentam que:

O novo universo gestado pelo modelo social opóe ao discurso colonizador expresso pelo saber normativo, médico, clínico e reabilitador uma práxis crítica, sociológica, política, inclusiva e contextualizada, gestando, quando interiorizada conscientemente, uma nova forma de pensar. E quando pensamos diferentes já não somos os mesmos. É claro que o surgimento de um novo homem apenas se materializará de fato com o abrolhar de uma nova sociedade (p.473).

Os autores destacam a importância de um novo modelo de sociedade que venha trazer novas reflexões, novos pensamentos, novo homem, nova sociedade. Acreditamos na sua relevância social também do surgimento de um modelo social da deficiência, sobretudo com a participação dos seus atores sócias, sua voz e sua própria história de vida. Segundo Silva (2007, p.32),

[...] ao contar sua vida, o sujeito fala de seu contexto - fala do processo por ele experimentado, intimamente ligado à conjuntura social onde ele se encontra inserido. Ao se trabalhar o vivido subjetivo dos sujeitos, através do método de História de vida, temos acesso à cultura, ao meio social, aos valores que ele elegeu e, ainda, à ideologia.

É hora de se escutar de forma minuciosa o que essas pessoas têm a nos dizer, é hora de se refletir, de analisar cada uma das suas histórias de vida. As pessoas com deficiência precisam 
ter autoria, vez e voz nos projetos para o seu desenvolvimento, fazer de fato parte de fato da sua família, da sua escola, da sua igreja, do seu trabalho, das suas associaçóes, das decisóes em grupo, das políticas públicas, enfim de toda essa sociedade.

Dentre estas pessoas com deficiência, encontram-se as pessoas surdas, mas especificamente aqui para este estudo, os líderes surdos, aqueles que não importando em que lugar, em que espaço, em que situação esteja, deixa a sua marca, a sua conquista, a sua fala (oral ou gestual), a sua escuta.

A pessoa surda que iremos nos reportar é aquela que se comunica normalmente por meio da linguagem gestual, no nosso caso a Língua Brasileira de Sinais (LIBRAS) e utiliza a visão para apreender o mundo, faz parte de uma minoria linguística e têm o direito de participar das experiências de aprendizagem com a mediação de sua língua natural. É detentora de uma identidade e uma cultura surda como elementos primordiais para sua diferença. Ratificamos as palavras de Skliar (1998) ao afirmar que, "a surdez constitui uma diferença a ser politicamente reconhecida; a surdez é uma experiência visual; a surdez é uma identidade múltipla ou multifacetada" (p.11).

Aceitar culturalmente as pessoas surdas é respeitar a luta historicamente construída e socialmente estabelecida; é combater a perversidade das açóes homogeneizadoras dos opressores que tentaram a aniquilar, de forma discriminatória e excludente. Vislumbramos fortes relaçóes entre o que preconiza Freire e os adeptos das atuais correntes denominadas "Estudos Culturais" e "Estudos sobre a Pessoa Surda".

Segundo Dorziat (1999) “a língua de sinais que dará condições de os surdos tornarem-se seres humanos em sua plenitude, através da apropriação dos conceitos científicos, disponíveis na educação formal” (p.29). No entanto, o uso dessa língua, apesar de critério básico, não deve ser visto como a solução de todos os problemas para a vida do surdo. Existem questóes de fundo que estáo presentes nas entrelinhas das relaçóes com o outro, caminhos para avançar, que possibilitam o desenvolvimento de questóes políticas e pedagógicas na busca de um novo cenário para uma sociedade de fato inclusiva, que se espelhe em uma nova forma de viver juntos, de conviver com o diálogo, com o respeito mútuo e ética solidária.

Concebemos os movimentos sociais como propulsores de oportunidades políticas e inerentes a história da humanidade com líderes que surgem para fazer a diferença dentro de contextos diversos e com a presença destes, testemunhamos o despertar de um novo horizonte, assistindo, entre o final do Século XX e início do Século XXI, a possibilidade da virada de uma página marcada pela segregação, discriminação e preconceito.

Vimos surgir o reconhecimento de alguns direitos das pessoas surdas e sua inserção nas políticas sociais. A primeira pesquisadora deste trabalho teve a oportunidade de vivenciar junto ao movimento surdo em Pernambuco, momentos na década de 80, em que encontros de surdos eram cada vez mais frequentes, como, por exemplo, o que acontecia em um bar no centro do Recife. Esses encontros foram fundamentais pelas várias conquistas, numa época ainda de resquícios de proibição da língua de sinais nas escolas. O bar pertencia a uma família de surdos e enquanto estabelecimento privado disseminava a cultura e a língua, fortalecendo a comunidade e contribuindo intensamente para a criação da primeira associação de surdos do 
estado, em 1985. Com ela, cursos de língua de sinais foram oferecidos para surdos e ouvintes. Continuando o movimento social das pessoas surdas, em 2002, foi inaugurado o escritório regional da Federação Nacional de Educação e Integração de Surdos (FENEIS) de Pernambuco.

Estas instituições tiveram destaque por impulsionar a participação dos surdos em todas as instâncias da sociedade. A FENEIS, que já existia em vários estados brasileiros, defendia os interesses da Comunidade Surda lutando pela integração e plena realização da cidadania do Surdo nas mais diversas áreas, tem caráter educacional, assistencial e sociocultural, além de disseminar a língua de sinais, oferecendo às pessoas ouvintes e surdas cursos para intérprete e instrutor de LIBRAS.

Nesse contexto, havia uma grande necessidade para que a comunidade surda fizesse parte ativa da sociedade, a Língua Brasileira de Sinais não era reconhecida e nem tinha o status de uma língua, e o seu náo reconhecimento era um dos motivos que mais dificultava a luta desta comunidade em busca de seus direitos.

Através de movimentos surdos organizados no país, é aprovada a atualmente conhecida como Lei da LIBRAS, Lei 10.436/2002 (BRASIL, 2002) que reconhecia no âmbito Nacional a LIBRAS como primeira língua da comunidade surda. Foi um passo extremamente importante para a inclusão da pessoa surda no âmbito social, depois veio a sua oficialização através do Decreto 5.626, de 22 de Dezembro de 2005 (BRASIL, 2005), que dispóe sobre a LIBRAS e sua inclusão como disciplina curricular, a formação do tradutor, do intérprete e dos docentes para o ensino de Libras. A inserção do intérprete no ambiente escolar também está assegurada na LDB 9394/96 (BRASIL, 1996) e nas Diretrizes Nacionais para a Educação Especial na Educação Básica (BRASIL, 2001).

Em 2012, ao mesmo tempo em que se vivenciava o movimento dos dez anos da Lei de Libras através de ampla repercussão nas redes sociais, a comunidade surda proclamava a instituição da Escola Bilíngue para Surdos, o que foi contemplado com a sua aprovaçáo na III Conferência Nacional dos Direitos da Pessoa com Deficiência.

Tal conferência que aconteceu em Brasília contou com cerca de três mil pessoas com ou sem deficiência, havia aproximadamente quarenta surdos de todo o Brasil. A primeira autora deste trabalho teve a oportunidade de estar presente como delegada, para ela foi emocionante e decisivo, sobretudo no momento da votação e aprovação da proposta da criação e implementação da Escola Bilíngue, que de acordo com o Decreto no 5.626/05, traz como a primeira língua de instrução a Língua de Sinais e a Língua Portuguesa, em sua modalidade escrita, como segunda língua.

Outro movimento de destaque para a comunidade surda foi o chamado "Setembro Azul", instituído no mês de setembro, que é comemorado o dia nacional do surdo, o projeto se disseminou por todo o país através de manifestaçóes públicas, palestras, debates, apresentação de teatro e outras atividades de visibilidade social.

Conquistas legais e sociais surgiram e ainda surgem para o delineamento de uma nova trajetória frente à inclusão das pessoas surdas. Entretanto, nada aconteceu por milagre ou mágica, a comunidade surda atravessou diversos movimentos de lutas, realizações, frustrações, sucessos e fracassos, mobilizaçóes, passeatas, reuniões, assembléias, debates e tantos outros. 
Contribuindo para essas transformaçôes, tem destaque as lideranças que surgem no interior das associaçóes e dos movimentos sociais, cada um com suas narrativas de história de vida tão significantes para o espaço em que ocupa e para a nova história da sociedade.

Dessa forma, acreditamos na relevância de um estudo sobre os fatores que podem levar uma pessoa ao empoderamento, à militância, à liderança. Será que, e até que ponto alguns aspectos sociais como família, escola, igreja, oportunidade de participação em associaçóes, amizades, nível sócio econômico, língua ou ate mesmo o próprio jeito de ser, a sua personalidade, influenciaram no processo de formação de um líder? Qual foi o papel de cadauma destas instituiçóes no desenvolvimento de sua liderança?

Para Morris e Staggenborg (2004), líderes de movimentos são “decisores estratégicos que inspiram e organizam os demais para participarem nos movimentos sociais" (p.171). Para eles, o líder é um articulador comprometido com a luta política, alguém que mobiliza recursos, estratégias e oportunidades e influenciam e organizam movimentos sociais.

Portanto, visando refletir sobre a trajetória de vida desses militantes líderes em sua complexidade, este artigo vem apresentar uma pesquisa que tem por objetivo analisar os fatores que levaram às pessoas surdas à militância e ao seu envolvimento em movimentos sociais, assim como as contribuições trazidas pela referida liderança.

\section{Método}

Privilegiando a abordagem qualitativa, nosso estudo foi desenvolvido através do método História de Vida, que segundo Glat e Pletsch (2009),

[...] a característica mais importante desta abordagem, portanto, é que a entrevista não é determinada a priori pelo pesquisador por meio de perguntas padronizadas e/ou previamente formuladas, mas sim pelos informantes (pesquisados): pela maneira como eles selecionam, interpretam, valorizam e transmitem suas experiências de vida (p.143).

É essa característica que distingue o método de História de Vida de outras formas de investigação. É pela entrevista aberta que a condução do estudo acontece e é dada pelos próprios participantes, a partir de sua visão de mundo. Também não há um tempo limite para esta aconteça, pode variar de acordo com a disposição do entrevistado assim como se encerrar quando este não tiver mais nada a acrescentar.

Glat e Pletsch (2009) destacam o uso de uma entrevista aberta, semi estruturada, sem roteiro pré-determinado enquanto especificidade e importância do referido método. Para ela, é a partir das colocaçóes do entrevistado que o entrevistador deverá formular novas questóes ou comentários se assim fizer necessário, porém, "[...] a direção da conversação e os tópicos a serem abordados são escolha espontânea do entrevistado" (p.143). Para essa estudiosa no assunto, o pesquisador não se preocupa em confirmar a "veracidade" dos fatos, pois para ele o importante é o ponto de vista do sujeito.

Serrano (2014), além de ratificar as ideias de Glat e Pletsch (2009) quanto às características da entrevista, lembra que esta deve ser aplicada com muita atenção para não perder o foco que se pretende, a linguagem deve ser acessível em um clima de empatia e confiança 
dos entrevistados com o entrevistador e o local deve possibilitar um desenvolvimento de uma entrevista de forma espontânea e tranquila para que não haja interrupção.

Trata-se de um método de grande responsabilidade por parte do investigador uma vez que precisa ser observados e considerados todos os dados colhidos, assim como o tempo cronológico, o período da investigação, pensar perguntas e temas provocadores caso seja necessário recorrer a eles, enfim conhecer aspectos inerentes ao assunto para que possa organizar a interpretação do entrevistado, compreender as experiências de destaque da vida dos entrevistados e a sua interpretação.

O método de História de Vida veio para se estabelecer na comunidade cientifica, e como afirma Silva (2007) tem validade e credibilidade como qualquer outro método, sobretudo porque revela que por mais individual que seja uma história, ela é sempre, ainda, coletiva, mostrando também o quão genérica é a trajetória do ser humano.

Durante o desenvolvimento de nossa pesquisa através das entrevistas abertas e gestuais (em LIBRAS), os informantes relataram o que achavam interessante, o que marcava a sua própria história de vida. Nessa direção, nos apoiamos em Glat et al.(2004, p.237), que afirma:

A partir desta abertura, o sujeito começa a relatar sua experiência, falando superficialmente sobre alguns aspectos e se detendo em outros que considera mais relevante. No decorrer da conversa o entrevistador é livre para fazer perguntas no sentido de clarificar ou aprofundar pontos mais diretamente ligados ao objeto de estudo.

Durante a realização das entrevistas, deixamos os atores sociais muito à vontade; as pesquisadoras direcionavam para que fossem relatadas questóes que remetessem aos seus objetivos.

Dai porque utilizamos o método História de Vida, por acreditar ser o mais adequado aos nossos objetivos.

Participaram do estudo cinco pessoas surdas, sendo quatro homens e uma mulher, todos adultos, com faixa etária entre 32 a 58 anos. Destes, quatro nasceram surdos e um adquiriu a surdez com dois anos de idade, três são oralizados, mas preferem se comunicar em LIBRAS, língua em que são fluentes.

Todos convivem com a comunidade surda, exercem ou exerceram cargo ou função de destaque nas associaçóes de surdos e pertencem a diferentes regióes geográficas.

Por questóes éticas, chamaremos os entrevistados pela letra E (de entrevistado), distinguindo - os pelos números de 1 a 5 (E1, E2, E3, E4 e E5).

\section{Resultados E Discussóes}

Além das contribuições teóricas de Beyer (2006), Dorziat (1999), Piccolo e Mendes (2013), Glat et al. (2004), Glat e Pletsch(2009), Lodi e Lacerda (2009),Silva (2007), Skliar (1998), dentre outros, demos ênfase aos estudos de Vygotski (1997), Vygotski (2008 apud PINO, 2000) e Freire (1987, 1996). Esses dois últimos autores sempre consideraram que as pessoas no exercício de suas atividades sociais, não representam apenas a imagem e semelhança 
do eu, mas, são possuidoras de representações próprias, inaugurando na sociedade, a visão de homem como agente de seu processo social.

Neste contexto, após analisar os resultados deste trabalho, percebeu-se que a família, enquanto grupo social primário e fator determinante para que o indivíduo se situe e interaja na sociedade, não apresentou participação significativa no processo de liderança dos nossos sujeitos. Nenhuma das cinco famílias dos entrevistados sabia língua de sinais, e também nunca influenciou ou levou o seu filho surdo para participar de alguma associação; dessa forma, as famílias, todas ouvintes, não promoveram maiores interaçóes sociais entre seus pares.

Não nos cabe aqui dizer a melhor forma da família de cada entrevistado agir diante de seu filho, esse não é o nosso objetivo, cada uma tem seu modo específico de pensar, acreditar, representar e viver. Dessa forma, nos apoiamos nos ensinamentos de Glat et al. (2004),

[...] Cada família enfrenta a deficiência de acordo com sua história, suas representaçóes, crenças, valores culturais, condiçóes objetivas e materiais, além da personalidade individual de cada membro. Certamente, as acomodaçôes que ocorrem na estrutura familiar sempre apresentam especificidades conforme o caso; porém não resta dúvida que a influência familiar é determinante para facilitaçáo ou impedimento do processo de integraçáo social do indivíduo com deficiências (p.5).

Para essa autora, é também através da identificação com os primeiros "outros significativos" e das reaçóes destes ao seu comportamento que "a criança tem seu primeiro contato com o mundo, aprende a desenvolver os papéis e atitudes essenciais para seu processo de socialização" (GLAT et al., 2004, p.2).

O binômio eu/outro veio se fizer presente na relação com o surdo, o outro surdo, como encontramos, por várias vezes, nas falas dos entrevistados. Os amigos surdos em quase sua totalidade se caracterizam como fator de destaque para a inclusão destas pessoas nas associaçóes. Em apenas um caso, a escola especializada para pessoas surdas foi a grande incentivadora, só E5 atribuiu esse outro para a escola e seus professores surdos.

Vejamos alguns fragmentos apresentados na fala de E4:

[...] conheci um amigo surdo que me chamou para conhecer outros surdos e depois fundamos uma Associação por livre e espontânea vontade, atualmente sou presidente dessa Associação dos Surdos.

Nesse caso, podemos nos reportar à concepção de sujeito histórico-cultural na concepção de Vygotski (2008 apud PINO, 2000) que aborda sobre o processo de interação social relacionado com a dialética existente no individuo com o meio em que vive, construindo conceitos e significados que vão mudando ao longo do tempo.

E4 relata ainda que:

[...] apenas conheci uma pessoa surda na Universidade, com 31 anos, e temos bastante contato sim, nossa amizade se mantém até hoje, foi através dele que conheci a comunidade surda, a cultura surda. 
Percebemos que ele se tornou um líder mesmo sem a escola ter contribuído para isso. Esse entrevistado entrou na universidade aos trinta e um anos, após uma longa história de evasão, afirma ainda que na sua escolarização não houve uma metodologia adequada para que ele aprendesse, tudo era para os ouvintes, não era atrativa e nem prazerosa. A escola regular que se diz inclusiva precisa ser um espaço público de educação com um olhar voltado para os alunos surdos. Lodi e Lacerda (2009) apontam que nessa escola:

A metodologia de ensino, o currículo e a cultura enfatizada são sempre os dos ouvintes, e o aluno surdo, por ser o único em sua classe, fica muitas vezes, à deriva, mesmo tendo garantidas condições especiais de acesso aos conhecimentos viabilizado pelo uso da Libras em sala de aula (p.17).

E5, o mais jovem dos entrevistados, relata com muito orgulho ter estudado em uma escola para surdos no ensino fundamental, desde os nove anos de idade. Dessa forma, o seu acesso é determinante para a constituição do sujeito surdo. Ao compararmos a história escolar de E4 com E5, observou-se que os dois percorreram caminhos pedagógicos bem diferenciados.

A escola também vem percorrendo novos caminhos, se transformando como resultado de intensas lutas e mobilização da comunidade surda, apresentando um novo perfil, o da chamada escola bilíngue para surdos. Esta escola surge com amparo legal, está contemplada no Decreto 5692/2005 e no Plano Nacional de Educaçáo (BRASIL, 2010) e deve ter em seu quadro profissional, instrutor de libras e professor bilíngue, assim como o currículo e uma metodologia voltada para as especificidades do surdo. Dessa forma, os conhecimentos devem ser viabilizados em língua de sinais, e a cultura surda ser apreendida, consequentemente a identidade surda ser desenvolvida.

Sobre a influência da igreja, constatamos que dos cinco entrevistados, três frequentaram uma igreja, um ainda mantém contato com os amigos surdos em associação, escolas, shopping, etc. E2, E3 e E4 fizeram parte de movimentos sociais de suas igrejas. Dessa forma, percebemos que a igreja, mais do que a família, contribuiu para o desenvolvimento do processo de liderança dessas pessoas.

Desde a idade média aos tempos atuais, a igreja é uma instituição que muito esteve presente na história de vida dessas pessoas. Mazzotta (2005) afirma que, por muito tempo estas pessoas foram colocadas à margem da sociedade, até o século XV existia a crença de que o surdo era um indivíduo primitivo, vivia totalmente à margem da sociedade, não tendo nenhum direito assegurado. Entretanto, a igreja teve um papel fundamental para a mudança dessa concepção, com o passar dos tempos, essa igreja cria no interior das mais diferentes religióes projetos de evangelização, pastorais, ou outros movimentos que passam a incluir pessoas surdas.

Em decorrência das tecnologias, podemos desfrutar de momentos de descontração, aprendizagem e conforto, pontos que se tornaram rotina de qualquer cidadão. Em contrapartida, tal avanço vem provocando mudanças comportamentais que muitas vezes podem levar ao isolamento e distanciamento de sentimentos que fortificam as relaçóes sociais, entretanto a sociedade atual está imersa na era da inclusão digital formando uma rede de relaçóes sociais das quais segundo Valente (1998), um novo tempo, um novo espaço e outras maneiras de pensar e fazer são exigidos na sociedade. Os nossos informantes também fazem parte desse novo espaço 
e formam verdadeiras teias de interação. Fato esse, que mostrou que foi um fator de empoderamento, mas que só aconteceu na fase adulta, exceto para E3 que fez uso na adolescência.

Sobre mercado de trabalho, também considerado elemento de empoderamento, todos os entrevistados trabalham desde a adolescência, com registro profissional, quatro são professores universitários e apenas um que é instrutor, e trabalha há oito meses sem registro na carteira de trabalho.

A identificação com outras lideranças foi um dado comum, ou seja, os cinco entrevistados foram estimulados por amigos surdos e tem ídolos ou admiradores surdos. Para Freire (1987), o outro representa formas de conscientização, dominação e poder, a imagem e semelhança do eu, mas que esse eu possui representações próprias, numa relação dialética constitutiva do eu e do tu.

E2 traz ainda um dado novo, o de entender que é surdo e ter direitos, o que ratifica o papel conscientizador da associação, quando relata "tenho um amigo surdo que é meu ídolo, comecei porque ele convidou, gostei, entendi que sou Surdo e que tenho direitos!”.

Todos os entrevistados mencionaram que, se sentiram prejudicados na comunicação com outras pessoas e ainda que foi fundamental a inserção no mundo da língua de sinais, na tomada de decisóes e no desenvolvimento de seu processo de liderança.

[...] já sofri muito na comunicação com outras pessoas, fui muito prejudicado, conheci libras ainda na infância, foi muito bom, facilitou minha participação na associação. O contato do surdo com a comunidade surda deve ser incentivado, pois a sua construção humana se dá prioritariamente no contato com os outros surdos, reconhecendo e valorizando uns aos outros e, sobretudo, aceitando sua condição de cidadão, a despeito de não ouvir (E5).

Lodi e Lacerda (2009, p.13) abordam que "a linguagem assume papel central na constituição dos sujeitos, pois os indivíduos constituem-se na interação das formas culturais da atividade, num curso de transformaçóes qualitativas dos seus modos de agir e pensar", o principal papel da linguagem é o de "consolidar e emergir" a participação do sujeito nas relaçôes sociais, na cultura, sua interação social no geral, assim desenvolver seu potencial de liderança, o que foi constatado pelos cinco entrevistados. Foi por meio da aprendizagem da língua de sinais que eles puderam dimensionar suas relaçóes sociais, suas aspiraçóes de justiça e liberdade, sua cultura e liderança.

Ao serem impulsionados a falar sobre a sua personalidade e características pessoais, todos relataram ser responsáveis, comprometidos, persistentes, se preocupam com o próximo o outro, o outro surdo, é importante que se considere não apenas as características do contexto em que essas pessoas estáo inseridas, mas suas falas, suas representaçóes.

[...] uma pessoa que se preocupa com o próximo, não aceito humilhações e desigualdades de meus amigos surdos, diante de várias barreiras e sofrimentos em minha vida, me tornei uma pessoa explosiva, mas náo sou acomodado, sempre crio coragem e cobro a sociedade e o setor público pelo direito de igualdade social de nossa comunidade. Sou uma pessoa responsável, quando assumo um compromisso, luto até o fim, é muito difícil desistir da luta, se perceber algo errado, grito, não sou de ficar em silêncio, igual vários surdos fazem, mas depois ficam 
comentando por "fora", se tiver que falar, falo na hora e na cara. Minha maior preocupação é que as crianças surdas não passem pelas mesmas barreiras, dificuldade e preconceitos que nós surdos passamos na infância e adolescência, e passamos até os dias atuais, minha luta é por uma sociedade mais justa e humana para todos os cidadãos, independente de sua diversidade social e cultural (E4).

E4 ao relatar sua personalidade ratifica as concepçóes de Freire (1987) quando aponta além da preocupação com o outro, uma relação de indignação, autonomia e libertação resultado da sua trajetória, sua história de vida, sua liderança surda. Para melhor percepção dos resultados obtidos apresentamos a seguir, no Quadro 1, uma síntese dos dados coletados e do perfil dos entrevistados.

\begin{tabular}{|c|c|}
\hline ASPECTOS REVELANTES & DADOS COLETADOS \\
\hline Tratamento adotado durante o estudo & E1, E2, E3, E4 e E5 \\
\hline Sexo & 04 homens e 01 mulher \\
\hline Faixa etária & 32 a 58 anos \\
\hline Nasceu surdo & E1, E2, E3 e E5. E4 ficou surdo com 02 anos \\
\hline Conhecimento e uso de libras & Todos os 05 entrevistados \\
\hline Reside em: & $\begin{array}{l}\text { São Paulo (capital), São Carlos, Rio de Janeiro e } \\
\text { dois em Recife, sendo um com atuaçáo em território } \\
\text { nacional. }\end{array}$ \\
\hline Oralizados & 03, mas preferem se comunicar em Libras \\
\hline Escolaridade & $\begin{array}{l}01 \text { graduado, } 01 \text { técnico, } 02 \text { especialistas e } 01 \\
\text { doutor }\end{array}$ \\
\hline $\begin{array}{l}\text { Famílias sabem Libras? levaram para alguma } \\
\text { associação?influenciaram para participar de alguma } \\
\text { associação? }\end{array}$ & Não \\
\hline Convivência com a comunidade surda & Todos os 05 entrevistados \\
\hline Idade que começou a participar de uma associação & Entre 14 a 31 anos \\
\hline Quem levou ou influenciou a participar de associação & $\begin{array}{l}\text { E1, E2 E E4 - amigos surdos } \\
\text { E3 - amigos surdos } \\
\text { E5 - escola }\end{array}$ \\
\hline Atuação na associação/ federação & $\begin{array}{l}\text { Secretário, diretor, presidente - voluntários e mili- } \\
\text { tantes, na esfera municipal, estadual e federal. }\end{array}$ \\
\hline Estudou com surdos: na ed. Infantil & E1 e E2 \\
\hline no ensino Fundamental & E1 e E3 \\
\hline no ensino Médio & E2 e E5 \\
\hline na educação Superior & $\mathrm{E} 1, \mathrm{E} 2, \mathrm{E} 4$ e E5 \\
\hline Estudou em Esc. Especial para surdos - ens. Fundamental & E5 \\
\hline Participação em igreja & E2 e E4 \\
\hline Participa ou participou de movimentos da igreja & E2, E3 e E4 \\
\hline
\end{tabular}




\begin{tabular}{|l|l|}
\hline Uso das tecnologias & $\begin{array}{l}\text { Todos têm e usam computador, internet, facebook, } \\
\text { skype e celular, apenas o whatsapp que náo é usado } \\
\text { por E1, fazem seu uso desde adulto, com exceçáo de } \\
\text { E3 que usou na adolescência. }\end{array}$ \\
\hline Trabalho & $\begin{array}{l}\text { Todos trabalham desde a adolescência, com registro } \\
\text { profissional, quatro sáo professores universitários e } \\
\text { apenas um que é instrutor e trabalha há } 8 \text { meses sem } \\
\text { registro na carteira de trabalho }\end{array}$ \\
\hline Aspecto linguístico & $\begin{array}{l}\text { Todos relatam ter sido prejudicado na sua comuni- } \\
\text { caçáo e, que a LIBRAS facilitou a sua vida. }\end{array}$ \\
\hline Traços da personalidade & $\begin{array}{l}\text { Todosrelatam ser responsáveis, comprometidos, per- } \\
\text { sistentes, se preocupam com o próximo - o outro, o } \\
\text { outro surdo. }\end{array}$ \\
\hline
\end{tabular}

Quadro 1 - Síntese dos aspectos relevantes dos dados coletados.

Fonte: elaboração própria.

\section{Conclusóes}

Pela análise das histórias de vida dos cinco entrevistados, foi possível constatar que o fator que mais contribuiu para o processo de formaçáo de um líder surdo foi a interação com outro surdo. Por várias vezes esse “outro' esteve presente nos relatos; a grande ênfase à influência dos modelos surdos, fato esse, que acreditamos ser melhor considerado no processo de constituição das identidades das pessoas surdas.

Ratificamos as concepçóes e ideias de Vygotski e Freire ao considerar o eu e o outro como possuidores de representaçóes próprias, fortalecendo a visão de homem como agente social. O binômio eu/outro foi ressaltado de forma constante nas relaçóes entre pessoas surdas.

O segundo fator de destaque relacionado aos nossos objetivos foi a importância da língua de sinais na formação da liderança surda. A LIBRAS foi fundamental para esse processo e para a participação e envolvimento nos movimentos sociais. A linguagem foi apresentada como ressignificadora de conhecimentos dentro de uma cultura própria e de respeito à cidadania.

Por vários anos, o surdo foi obrigado a falar uma palavra que não era sua, agora, ele é parte ativa e decisiva nos movimentos sociais, fazem a diferença dentro de contextos diversos. Por outro lado, a escola que diz incluir, formar sujeitos críticos e transformadores, nos modelos tradicionais em que se encontra não teve representação marcante, apenas a escola especial para surdos foi relevante, para a formação da sua liderança. Nesse contexto, as escolas bilíngües para surdos possivelmente vão se enquadrar nos fatores desencadeadores de um novo modelo social.

A família de acordo com os resultados da pesquisa não foi fator determinante, a igreja foi um pouco mais além, o uso das tecnologias apesar de bastantes significativas, só chegaram para essas pessoas quando elas já estavam dentro dos movimentos sociais. 
Foi de grande importância para esse estudo, a escolha do método História de Vida, por ter possibilitado um momento de "escuta", dar "voz" para os nossos entrevistados, e com a sua interpretação, apreender e aprender sobre a história de vida desses e de tantos outros lideres surdos, a sua trajetória em movimentos sociais.

Revisitando o novo modelo social da deficiência, percebemos que a localização da deficiência não está nas pessoas, mas na forma como a sociedade se apresenta. Isso persistirá enquanto não se apresentar saídas reais e dignas para um modelo de organização humana justo, com espaço para todos e para cada um, segundo as suas especificidades.

Finalmente, o estudo realizado nos remete a repensar uma mudança social que ofereça mais espaço e oportunidades para inclusão de pessoas surdas. Também é importante a realização de pesquisas através da utilização do método de História de Vida, que a exemplo desse estudo, nos permite afirmar que nosso objetivo foi atingindo, vez que foi possível analisar os fatores que levaram pessoas surdas a assumirem a função de liderança em movimentos sociais.

\section{REFERÊNCIAS}

BEYER, H. O. Inclusão e avaliação na escola de alunos com necessidades especiais. Belo Horizonte: Mediação, 2006.

BRASIL. Ministério da Educação. Secretaria de Educação Básica. Diretrizes nacionais para a educação especial na educação básica. Brasília, DF: MEC, 2001.

BRASIL. Casa Civil. Subchefia para Assuntos Jurídicos. Decreto no 5.626, de 22 de dezembro de 2005. Disponível em: <http://www.planalto.gov.br/ccivil_03/_ato2004-2006/2005/decreto/d5626.htm>. Acesso: 04 fev. 2014.

DORZIAT, A. Concepçóes de surdez e de escola: ponto de partida para um pensar pedagógico em escola pública de surdos. 1999. 230f. Tese (Doutorado em Educação Especial) - Programa de Pós-Graduação em Educação Especial, Universidade Federal de São Carlos, São Carlos, 1999.

FREIRE, P. Pedagogia do oprimido. Rio de Janeiro: Paz e Terra, 1987.

FREIRE, P. Pedagogia da autonomia: saberes necessários à prática educativa. Coleção Leitura. São Paulo: Paz e Terra, 1996.

GLAT, R.; PLETSCH, M.D. O método de história de vida em pesquisas sobre auto-percepção de pessoas com necessidades educacionais especiais. Revista Educação Especial, Santa Maria, v.22, n.34, p.139-154, 2009.

GLAT, R. et al. O método de história de vida na pesquisa em educação especial. Revista Brasileira de Educação Especial, Marília, v.10, n.2, p.235-250, 2004.

LODI, A. C. B.; LACERDA, C.B.F. Uma escola duas linguas: letramento em língua portuguesa e língua de sinais nas etapas iniciais de escolarização. Porto Alegre: Editora Mediação, 2009.

MAZZOTTA, M. J. S. Educação especial no Brasil: história e políticas públicas. 5.ed. São Paulo: Cortez, 2005.

MORRIS, A.; STAGGENBORG, S.L. Social movements. In: NOW, D.; SOULE, S. A.; KRIESI, H. (Org.). The blackwell companion to social movements. Oxford: Blackwell Publishing, 2004. 
PICCOLO, G. M.; MENDES, E. G.Contribuiçóes a um pensar sociológico sobre a deficiência. Educação e Sociedade, v.34, n.123, p.459-475. 2013.

PINO, A. O social e o cultural na obra de Vygotski. In: Educação e Sociedade, v.21, n.71, p.45-78, 2000. Disponível em <http:/www.scielo.br/pdf/es/v21n71/a03v2171.pdf>. Acesso em: jul. 2014

SERRANO, E.A. P. Estrategias familiares de vida y violencia: historias de vida em lãs comunidades La Yabita y Cerro Verde de Holguín. Holguín: 2014.

SILVA, A. et al. Reflexôes sobre o método de história de vida. Revista Mosaico: estudos em psicologia, v.1, n.1, p.25-35, 2007.

SKLIAR, C. A. Surdez: um olhar sobre as diferenças. Porto Alegre: Editora Mediação, 1998.

VALENTE, J. A. Informática na educação: a prática e a formação do professor. In: ENDIPE ENCONTRO NACIONAL DE DIDÁTICA E PRÁTICA DE ENSINO, 9., 1998, Águas de Lindóia. Anais... Águas de Lindóia, 1998. p.1.

VYGOTSKI, L. S. Obras Escogidas - Tomo V. Fundamentos de defectologia. Madrid: Visor. 1997. 6

Recebido em: 16/06/2015

Reformulado em: 10/03/2016

Aprovado em: 15/03/2016 
VASCONCELOS, N.A.L.M.L. et al. 